DOE/CE/20505-2

$$
R-4110
$$

$+$

\title{
Evaluation of Higher Distribution and/or Utilization Voltages \\ First Interim Report (December 1978) Literature Search and Problem Definition
}

Published April 1981

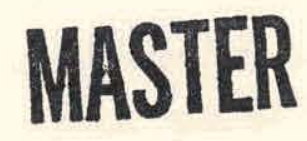

Prepared for:

U.S. Department of Energy

Assistant Secretary for Conservation and Renewable Energy Division of Electric Energy Systems

Under Contract No. AC01-78 ET 20505 


\section{DISCLAIMER}

This report was prepared as an account of work sponsored by an agency of the United States Government. Neither the United States Government nor any agency Thereof, nor any of their employees, makes any warranty, express or implied, or assumes any legal liability or responsibility for the accuracy, completeness, or usefulness of any information, apparatus, product, or process disclosed, or represents that its use would not infringe privately owned rights. Reference herein to any specific commercial product, process, or service by trade name, trademark, manufacturer, or otherwise does not necessarily constitute or imply its endorsement, recommendation, or favoring by the United States Government or any agency thereof. The views and opinions of authors expressed herein do not necessarily state or reflect those of the United States Government or any agency thereof. 


\section{DISCLAIMER}

Portions of this document may be illegible in electronic image products. Images are produced from the best available original document. 


\section{NOTICE}

This report was prepared as an account of work sponsored by the United States Government. Neither the United States nor the United States Department of Energy, nor any of their employees, makes any warranty, express or implied, or assumes any legal liability or responsibility for the accuracy, completeness, or usefuiness of any information, apparatus, product, or process disciosed, or represents that its use would not infringe privately owned rights. Reference herein to any specific commercial product, process, or service by trade name, mark, manufacturer, or otherwise, does not necessarily constitute or imply its endorsement, recommendation, or favoring by the United States Government or any agency thereof. The views and opinions of authors expressed herein do not necessarily state or reflect those of the United States Government or any agency thereof.

\section{Avallable from:}

National Technical Information Service (NTIS)

U.S. Department of Commerce

5285 Port Royal Road

Springfield, Virginia 22161

\begin{tabular}{|c|c|}
\hline Lce: & $\begin{array}{l}\text { Printed Copy: } \\
\text { Microfiche: }\end{array}$ \\
\hline
\end{tabular}


- Evaluation of Higher Distribution and/or Utilization Voltages

First Interim Report (December 1978) Literature Search and Problem Definition

Published April 1981

Prepared for:

U.S. Department of Energy

Assistant Secretary for Conservation and Renewable Energy Division of Electric Energy Systems

Washington, D.C. 20461

Prepared by:

Econ, Inc.

Princeton, New Jersey 08540

Under Contract No. AC01-78 ET 20505

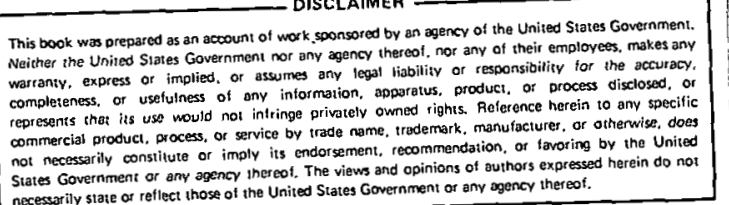




\section{TABLE OF CONTENTS}

Chapter

$\underline{\text { Page }}$

List of Figures

iii

1. Preface :

2. State-of-the-Art of Higher Distribution/Utilization Voltage

Analysis and Technology

2.1 Primary and Secondary Distribution System

2

2.1.1 Relevant Literature

2.1.2 State-of-the-Art

2.1.3 Ferroresonance

4

6

8

2.2 End Use Elements - 11

2.2.1 Motors 11

2.2.2 A-C Watthour Meters 23

2.2.3 The Potential Impact of Electric Vehicles 25

2.3 Economics and System Analysis/Optimization 27

2.3.1 Distribution Economics 27

2.3.2 Factors Affecting Distribution Costs 28

2.3.3 Present Trends 29

2.3.4 Distribution and Utilization System Optimization 30

3. Potential Advantages and Disadvantages of Higher

Distribution/Utilization Voltages

3.1 Primary and Secondary. Distribution System 34

3.2 End Use Elements 36

4. Bibliography 38

4.1 Primary and Secondary Distribution System 38

4.2 End Use Elements 44

4.3 Economics and System Analysis/Optimization 40 


\section{LIST OF FIGURES}

\section{Figure}

2.1 Series RLC A-C Circuit

2.2 One Phase Energized.
Page

9

9 


\section{PREFACE}

A literature search has been conducted on the economics and technical problems associated with the use of higher voltages in both the primary distribution and secondary utilization systems. After a literature review and evaluation, an assessment of the state-of-the-art with regard to high voltage has been made and is presented for the primary and secondary distribution systems, end use elements, and economics and system analysis or optimization in Sections 2.1, 2.2 and 2.3, respectively. An annotated bibliography is provided for each of the three categories in Sections 4.1 through 4.3.

A comprehensive list of potential advantages and disadvantages of higher primary distribution and utilization voltages has also been prepared and is presented in Sections 3.1 and 3.2. 


\section{STATE-OF-THE-ART OF HIGHER DISTRBUTION/UTILIZATION \\ VOLTAGE ANALYSIS AND TECHNOLOGY}

\subsection{Primary and Secondary Distribution Systems}

Considerable effort has been devoted to the development and refinement of . electric distribution systems to provide service to consumers at reasonable cost and of high quality and reliability. This effort is well documented in the literature and is concerned with the design of distribution substations, as well as primary and secondary distribution circuits, system voltage regulation, system reliability and protective device coordination, the evaluation of system losses, and the features and design considerations inherent with the application of higher primary and secondary distribution'voltages.

The principal components of the distribution system are the distribution substation, the primary circuit, the distribution transformer, the secondary circuit, and the customer's service drop. The distribution substation transforms transmission voltage to regülated primary distribution voltage and provides switching capability to minimize the system impact of random faults and planned maintenance. The primary circuit carries the electrical energy at primary voltage to geographically dispersed locations to supply both distribution transformers and larger consumers-that elect to accept service directly at primary voltage. The primary circuit is designed to provide a reliable supply with the capability for rapid fault isolation and load restoration. The distribution transformer reduces primary voltage to a lower secondary level for the supply of residential and small commercial consumers. The secondary circuit distributes the electrical energy to a number of consumers in the area of the distribution transformer. The consumer 
service drop is a set of conductors which connects the consumer's receiving point with the secondary circuit and is sized to carry only that consumer's expected demand.

An analytical model of the distribution system is to be created which will provide system cost and energy efficiency as a function of choice of primary and secondary voltage levels, area load characteristics (density, load profile, growth), and cost escalation and inflation rates. The primary and secondary distribution systems will be of radial configuration (simple or open-looped). The load will be assumed to consist only of residential or small commercial consumers. Distribution substations will be of unit construction, and transmission costs to supply these substations will be omitted from the analysis. Essentially, the analytical model will be geared to the optimization of design and operation of the primary and secondary circuits. To be considered are primary voltages up to $69 \mathrm{kv}$ and secondary voltages up to 920 volts.

In the distribution system modeling to support the evaluation of cost, performance and energy losses of the system as a function of primary and secondary voltage levels, consideration must be given to the technical requirements of circuit design that relate to (1) maintaining a consistent level of reliability and quality of service in terms of continuity and voltage level; (2) suppression of voltage surges arising from fuse or switched interruption of fault currents, ferroresonance and lightning; (3) specification of basic insulation level for equipment and apparatus; (4) limitation of available fault currents; (5) safety, appearance, constructability and maintainability; and (6) economics in the selection of components.

For specified primary and secondary voltages and any set of area load characteristics, the modeling effort will support the analytical optimizations of (1) 
voltage profile among primary circuit, distribution transformer, secondary circuit, and consumer service drop through choice of capacitor allocation, size of distribution transformer, and the relative lengths of primary and secondary circuits; (2) conductor sizing and rating for primary and secondary circuits; and (3) distribution transformer sizing and secondary circuit length.

Evaluation of the cost and energy efficiency of optimal circuit designs for different combinations of primary and secondary voltage levels under various load, inflation, and equipment and energy cost conditions will provide the basis for assessing the benefits of higher primary and/or secondary voltages.

\subsubsection{Relevant Literature}

The literature relevant to the evaluation of higher distribution voltages centers around the areas of (1) economics, features and design considerations of primary voltages up to $34.5 \mathrm{kv}$ and of secondary voltages up to 480 volts; (2) optimization in the sizing and loading of distribution transformers and secondary circuits; (3) optimization in the selection and loading of primary and secondary conductors; (4) optimization in the allocation and sizing of distribution capacitors; (5) evaluation of losses and their cost; (6) optimization of circuit geometry; and (7) maintenance of circuit reliability as voltage is increased. The accompanying annotated bibliography is not comprehensive, but is intended to represent the breadth and extent of previous efforts.

There are two principal directions taken in the discussion of higher primary voltages. One provides a basis for comparing the relative economics of different voltages; the other centers on the technical considerations in adopting higher voltage. Lawrence, Reps and Patton - I (1960) and Smith (1961) represent efforts by principal equipment suppliers and consultants to the electric utility industry to compare the benefits of different voltage levels. Recommendations are based on 
repeated system analyses using various combinations of primary voltages and load densities. Park (1974) describes a utility's comparison using an analytical econometric model which is of particular interest in the current work. The second type of discussion of higher primary voltages, Nickel (1974) and Procario (1977) considers technical issues which include reliability, surge suppression, fault current limitation and basic insulation levels. Concerning the use of higher secondary voltages, the literature is represented by Campbell and Sinnott (1957) and Zimmerman and Lokay (1956), and reflects the concern of the electric equipment industry with the potential benefits of higher utilization voltages.

Considerable effort has been devoted to the determination of the optimal sizing and loading of distribution transformers and secondary circuits. Burandt, Hughes, Patton and Reps (1961), Lawrence, Reps and Patton - I (1960) and Mitchell, Sweeny and Cantwell (1958) reflect efforts of the equipment and consultant industry to provide planning guidelines. Klein (1959) provides a contribution by an electric utility. These papers describe an optimization by cutand-try where cost calculations are made for various combinations of load, transformer and secondary conductor sizes, and secondary circuit length. Anderson and Thiemann (1959), however, formulate the problem analytically, and their article is consequently of interest in the current work.

Optimal conductor sizing is achieved by equating the incremental cost of losses with the incremental investment cost of conductor. Giedlinski (1978), Comellini and Noferi (1977), Querubin, Cuervo and Navas (1975) and Anderson and Thiemann (1959) offer means of analyzing this balance.

Of particular importance in the evaluation of higher distribution voltages is the analysis of losses and how their magnitude is affected by the specification of permissible voltage drop and circuit length, by the application of capacitors, and by 
the choice of circuit geometry. Chang (1972) offers a method for the, economic allocation of capacitors for the reduction of losses and maintenance of desired voltage. For the analysis of voltage drop and circuit losses in circuits of generalized configuration, Schulz (1978) is valuable. These two references provide analytical expressions for voltage drop and demand losses in terms of geographical area and conductor parameters. Optimization of circuit length and circuit pattern are considered in Hopkins and Samson (1954), Merlin and Bade (1975), Wall, Thompson and Northcote-Green (1978) and Wormer (1954). Material in these references is expected to provide the basis for the determination of the optimal area coverage of primary and secondary circuits as a function of load characteristics.

Expressions have been derived for the calculation of demand losses for singleand three-phase circuits and transformers in Chang (1968), (1970) and (1973) and Schulz (1978). An annual loss factor is commonly used to calculate annual energy loss from peak demand loss. Also contributing to the evaluation of losses and their cost are Comellini and Nofer i (1977), Hazan (1969) and Hopkins and Samson (1954).

As loading capability and length of circuit increase with increasing primary distribution voltage, more consumers become subject to interruption when a fault occurs, and such a fault is more likely with the increased exposure of a longer line. Service reliability is improved by automatic sectionalization of the fault followed by automatic transfer of isolated unfaulted sections to adjacent circuits. Gay (1978) and Nickel (1974) discuss how the sectionalization and transfer capability is planned and implemented.

\subsubsection{State-of-the-Art}

Although large consumers of electrical energy, such as metal refineries, may receive their services at voltages as high as $230 \mathrm{kV}$, and occasionally rural 
secondary loads may be tapped on to subtransmission operating at 46 or $69 \mathrm{kV}$, primary distribution systems do not currently make general use of voltages in excess of $34.5 \mathrm{kV}$. Since its first use as a primary distribution voltage by Virginia Electric and Power Company in $1963,34.5 \mathrm{kV}$ has led to an evolution in equipment and system design which even now is continuing. Each utility which adopts $34.5 \mathrm{kV}$ must balance system cost and performance to satisfy the consumers which it serves.

Equipment designed for application in a $34.5 \mathrm{kV}$ distribution system is well developed. Equipment insulation level is designed to withstand a basic impulse level (BIL) of 125 to $150 \mathrm{kV}$ with a tendency toward the use of $150 \mathrm{kV}$. Minimal consumer interruption during circuit maintenance has led to the development of inexpensive switches and connectors capable of opening the circuit under loaded conditions. Three-phase switches have been incorporated into distribution transformers to avoid single-pole switching and the accompanying problem of ferroresonance. Cable insulation requirements for use in the distribution system are not as great as those for subtransmission. Insulation wall thickness has consequently been reduced to match the performance requirements perceived for distribution at $34.5 \mathrm{kV}$.

Metal enclosed bus and switching compartments have been developed for use in distribution substations for voltages up to $34.5 \mathrm{kV}$ to provide an economic, compact installation. Development work is still needed on similar designs for use at higher voltages. In general, the substation employs equipment of the same class as used in transmission and consequently is currently available for higher voltages.

Circuit designs for $34.5 \mathrm{kV}$ vary from utility to utility and tend to provide service which conforms with the general expectations of the consumers served. The nature of current sectionalization and load transfer capability evolves as cost, 
performance and consumer satisfaction are maintained over time. Utilities that have had more experience with $34.5 \mathrm{kV}$ tend to better understand their consumers' expectations and are likely to be closer to their ultimate circuit design.

The problem with ferroresonance is present at $34.5 \mathrm{kV}$, but is usually avoided by adopting certain design and operating procedures. At higher voltages; however, it is uncertain how severe the problem may be. Ultimately, it may be necessary to use individual transformers for each of the three phases to avoid magnetic coupling, and to connect these in wye-wye configuration. Motors may have to be designed for lower voltage to match the lower phase-to-phase voltage available from a wye connection.

Currently, aerial $34.5 \mathrm{kV}$ may be routed along a highway whereas aerial circuits employing $69 \mathrm{kV}$ are required to have a separate right-of-way. The costs and benefits of this difference need further exploration. Because of greater insulation requirements, the smallest economic size of distribution transformer is not yet known for voltages greater than $34.5 \mathrm{kV}$.

In summary, the state-of-the-art for the application of distribution voltages higher than $34.5 \mathrm{kV}$ is poorly developed. This is so because little experience has been gained in balancing costs and performance in the satisfaction of the desires of the consumer.

\subsubsection{Ferroresonance}

Ferroresonance is a special case of series resonance. For an RLC circuit, such as that shown in Figure 2.1, the circuit becomes resonant when $X_{L}$, the inductive reactance, becomes equal to $X_{C}$, the capacitive reactance. For this condition, the current is limited only by the resistance, $R$, and may be very large if $R$ is small. This results in a very high voltage across the inductance and capacitance. 


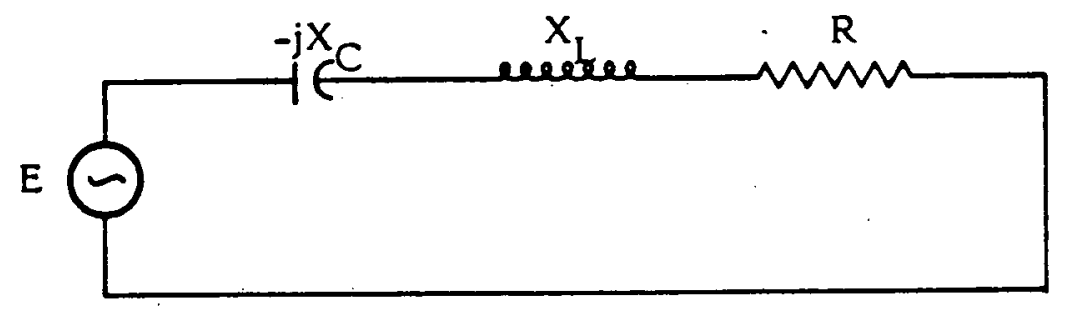

FIGURE 2.1 SERIES RLC A-C CIRCUIT

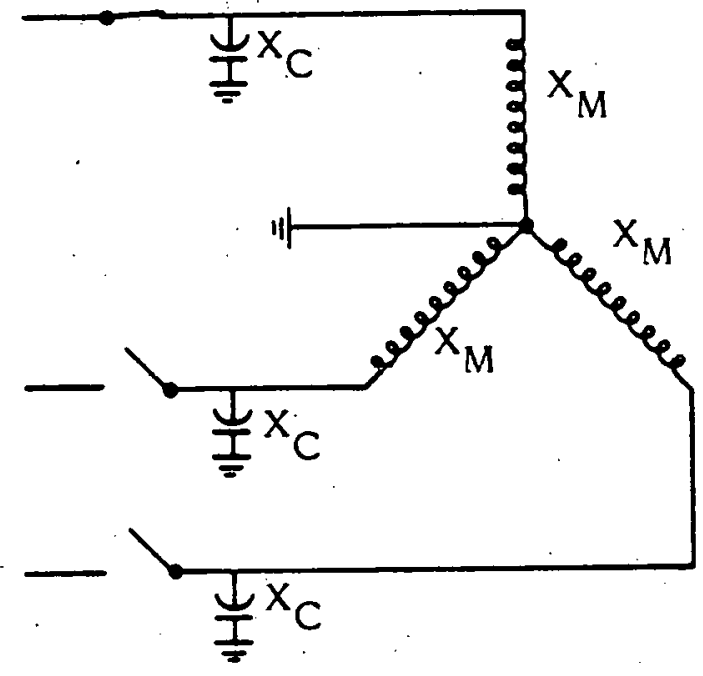

FIGURE 2.2 ONE PHASE ENERGIZED 
In circuits. for which $X_{L}$ is independent of the current, only one value of $X_{L}$ will match with $X_{C}$ at resonance. For a transformer winding, $X_{L}$ is not constant throughout each cycle of applied voltage. It varies depending on the degree of saturation of the transformer core, and the inductive reactance presented by the transformer winding will vary throughout each cycle of applied voltage. Each of these values will resonate with a given value of capacitive reactance. Hence, with higher voltages, more resonant points can occur during each cycle, thus causing overvoltages across the transformer and possibly leading to failure of the insulation. This problem may be aggravated by the use of distribution transformers rated for higher voltages.

The conditions under which series resonance may occur in a distribution tranformer system are described below.

1. During certain single-pole switching operations.

In Figure 2.2, it is shown how with one switch closed to a three-phase transformer bank circuits to ground may occur which can become resonant. The occurrence of resonance may result in overvoltages which may damage the transmission line or the transformer.

2. Ferroresonance may occur when single-phase switching devices are used, since in this case one contactor may close before the other two. The following conditions are necessary for the occurence of ferroresonance on distribution transformer. systems:
A. System grounded at the source but with no ground at the transformer bank.
B. One or two primary phase conductors open.
C. No load on the transformer bank.
D. Primary circuit capacitance and transformer reactance at critical values.

If any of the above can be avoided, ferroresonance is far less likely to occur.

Methods of preventing ferroresonance from occurring in distribution transformer systems have been studied in recent years. In his paper, "Ferroresonance on. 
Rural Distribution Systems", published in February 1973, Eugene C. Lister suggests the following preventative measures:

1. Limit length of transmission line or cable between the transformer bank and the source to limit capacitance to ground.

2. Replace single-phase cutouts and oil circuit reclosures with 3-phase reclosures. This does not completely eliminate ferroresonance, but it does reduce the possibility of accidental opening of a primary phase conductor.

3. Tests have shown that a small amount of resistive load on the secondary side of a transformer bank (approximately 5 percent of the bank rating) will reduce the probability of ferroresonance at the cost of extra losses.

4. Grounding the neutral of a three-phase distribution transformer bank is helpful in preventing ferroresonance. Reference to Figure 3 shows that grounding the neutral bypasses the cable capacitance to ground and can be effective in preventing a series resonant circuit from occurring.

5. Experiments have shown that grounding the neutral through a resistor of the proper size will prevent ferroresonant overvoltages. The value of the grounding resistance should be limited to approximately 5 percent of the magnetizing reactance of each transformer. Its value must also be such as to limit the transformer current to a value not greater than rated for a line-to-ground fault.

\subsection{End Use Elements}

\subsubsection{Motors}

About 60 percent of the appliances sold today in the United States use an electric motor of some kind. No study of higher utilization voltages can, therefore, ignore the effect of higher voltages on the design and operation of this equipment.

The efficiencies of electric motors to be studied in conjunction with this project vary from as low as about 10 percent for small shaded-pole fan motors to about 85 percent for polyphase induction motors up to approximately 5 horsepower. Most residential motors are rated at less than $1 \mathrm{hp}$, although a few as large as 4-5 hp are installed in residential air conditioning units. These motors, in general, operate on single-phase alternating current--the only service utilities sell to 
households. Commercial establishments use a greater variety of motors of larger sizes. Unlike residential customers, commercial customers can obtain three-phase alternating current. This service offers larger businesses the greater economy of purchase, operation and maintenance associated with polyphase motors.

Most motors built in recent years are designed.to save. on materials; which represent some energy and labor savings during construction, but sacrifice efficiency. The combination of marketing demands, engineering decisions and customer desires has led to this approach.

There is, at present, a movement afoot to construct electric motors with designs and resulting efficiencies similar to those made 30 to 40 years ago, but using the best modern insulating materials. It is felt that magnetic materials used should be selected for-optimum performance with minimum losses, and the bearings should be of the best quality, easily replaceable with ordinary tools. The type of motor being proposed would probably cost about twice as much as a motor of corresponding rating costs today. It is believed that this increased cost could partially be offset by complete standardization of frames and mounts.

Most of the output from motors in homes and light commercial businesses is used to run refrigerator and space conditioning compressors. Virtually all refrigerators and air conditioners made for residential use, and the majority of those made for commercial use employ a hermetically sealed motor compressor unit. This means that the motor and compressor are directly coupled and sealed inside a welded steel case. The advantage of this construction is that the coupled system runs more quietly, occupies less space and requires less maintenance. It would be counterproductive to attach an efficient and long-lasting motor inseparably to a compressor destined to wear out within a few years, and then to add a housing which makes repair impossible and salvage of copper difficult. The 
proposal being made by some motor manufacturers to return to more efficient motors would, therefore, also require a return to an open-type, coupled (possibly belt-driven) compressor. This change would also be for the better, since beltdriven compressors run at lower rotational speeds and have potential for longer life. Even more important, the waste heat from the motor is not added to the working fluid as in the case of hermetic machines. Thermodynamically, this is advantageous, for it permits one to obtain more refrigeration per unit motor power. There would, therefore, be a further gain in conservation of energy resources.

A study of the existing literature shows that little has been done to study the effects of higher utilization voltages for household refrigerator motors. Motors for this service are generally of the split-phase 4 -pole, $60 \mathrm{~Hz}, 1725 \mathrm{rpm}$ type. Ratings used vary from one-tenth to about one-quarter horsepower, but the horsepower rating is not of great importance since the motor is usually designed for a specific compressor application.

In some instances, it is desirable to use a capacitor-start, induction-run motor to obtain a greater starting torque. However, this would be less likely in a household refrigerator than in a commercial application.

Domestic refrigeration motors are, at the present time, designed for 115 volts, $60 \mathrm{~Hz}$. The export trade requires 115 and 200 to 250 volt, 50 and $60 \mathrm{~Hz}$ motors. Reactors and transformers are available for use with standard 115 volt, $60 \mathrm{~Hz}$ domestic refrigerator motors to make possible operation of domestic units on most of the voltages and frequencies encountered in export trade.

At the present time, voltages as low as 70 and as high as 130 are found in some areas. This is too great a range for the satisfactory operation of most existing motors. A suitable motor for this voltage range would be excessively large 
and lead to additional costs. Generally, present household refrigerators are designed for a working voltage range of 100 to 125 volts. With higher utilization voltages, it must be assumed that the motors will also be subjected to voltage fluctuations. However, it is anticipated that this problem will not be as great in a system designed for higher utilization voltages. Such systems inherently have less serious voltage regulation problems.

A single-phase motor will not start without some auxiliary starting means. From a practical standpoint, it is necessary to wind a starting winding, displaced 90 electrical degrees from the running winding, into the stator. The combination of both windings produces sufficient torque to start and bring the motor up to a predetermined speed. The starting winding is usually cut out at a speed just above the breakdown-torque point of the motor operated on the main winding alone. $A$ current- or voltage-operated relay is generally used to cut out the starting winding. Centrifugal switches are not used to cut out the starting winding in hermetic units because of their inherent sparking, but time-delay units may be used.

A current-type relay is used in many household refrigerator applications. The current coil of such a relay is connected in series with the main winding and so designed that, after the line switch is closed, the armature of the relay drops out, opening the contacts and disconnecting the starting winding. This type of relay has proved to be very successful when used with household refrigerator motors. Timedelay relays of the thermal type are also used in many household refrigerators for opening the starting-winding circuit.

Voltage-type relays used for starting single-phase motors normally have their contacts closed. The motor design must be such that the voltage across the starting winding will increase appreciably with speed. The increased voltage moves the relay armature to open the contacts. This type of relay can be used only with 
capacitor-start motors. Voltage-operated relays designed for use at higher voltages would have to have coils designed for considerably more turns of much finer wire. There would also be problems associated with the tendency toward greater arcing at the contacts.

Typical starting capacitors used with capacitor-start, single-phase induction motors are a-c electrolytics rated for twenty, three-second duration starts an hour and 130 volts rms. Going to higher utilization voltages may necessitate going to series-parallel connections in starting capacitors in order to obtain the required capacitance and a reduction in capacitor voltage to allowable levels. If measures such as this are not adequate, it may be necessary to use permanent-type oil-filled capacitors or a combination phase converter and a 3-phase motor. All of the alternatives result in greater cost.

Heat is generated in refrigerator compressor motors as a result of the motor losses. Heat is also generated in the compressor by the compression of the refrigerant and by the friction in the common bearing. This heat must be dissipated by radiation and convection, conduction through the compressor mountings and connections, and flow of gas through the compressor. Fins on the compressor shell or forced circulation of air by fans increases the heat dissipation.

Overheating of a hermetic motor may be caused by overloading, undervoltage, overvoltage or stalling the motor. Abnormal ambient temperature, failure of the ventilating system and, in some cases, loss of refrigerant also contribute to overheating. A thermal overload protector (TOP) should be selected to give satisfactory ultimate trip and locked rotor protection to the running winding. At the present time, the highest TOP voltage rating approved by Underwriters' Laboratories is 480 volts on a $4-3 / 8$ inch outside diameter motor made for 3-phase operation. Thus far, no protector for this voltage rating has been developed for 
starting service on any 480 volt single-phase motor. This may be because of the close contact spacing used in most modern protectors. In recent years, as motors have been packed into less and less space, temperature protection problems have worsened. It has become more and more difficult to find room for the protector.

In going to higher utilization voltages, it may thus be necessary to employ current-sensing devices located remotely from the motor. This type of protection may take the form of fuses, dashpot overload relays, or thermal overload relays and is what is used on 480 volt industrial-type a-c motors.

About two years ago, an electronic starting circuit was developed for use with home appliances. This circuit is described by Scheuer and Sample in their paper, "Adjustable Threshold Electronic Motor Starting System". This circuit needs further investigation to determine the present state of its development and whether or not it overcomes the problems arising from the use of conventional electromechanical motor-starting systems on equipment with higher utilization voltages.

It is well known that, as a first approximation, a motor of a given hor sepower and speed rating requires about the same amount of copper regardless of the voltage rating. If higher utilization voltages necessitate going to an oversized frame, the higher voltage motor may require increased copper. When higher voltages are used, the motor must be designed for more turns of finer wire. As the wire becomes finer, the ratio of its copper cross-section to its total cross-section (space factor) is reduced. The windings also become less able to withstand the mechanical stresses associated with fault currents. Because of the greater amount of insulation required in the higher voltage motors, they are, in general, less efficient. 
The equation governing preliminary selection of the winding for a three-phase induction motor is as follows:

$$
E p h=4.44 \mathrm{Nph} f \emptyset \mathrm{K}_{\mathrm{p}} \mathrm{K}_{\mathrm{d}}
$$

where

$$
\begin{aligned}
& \text { Eph }=\text { voltage induced per phase in the stator winding by the resultant } \\
& \text { air-gap field } \\
& \text { Nph }=\text { series turns per phase } \\
& f \quad=\text { frequency of the stator current in } \mathrm{Hz} \\
& \left.\emptyset \quad=\quad \text { flux per pole in webers ( } 1 \mathrm{w}=10^{8} \text { lines }\right) \\
& K_{p}=\frac{\text { voltage induced in a short-pitched coil }}{\text { voltage induced in a coil spanning } 1 \text { pole pitch }} \\
& K_{d}=\frac{\text { phasor sum of coil voltages of } 1 \text { phase }}{\text { arithmetic sum of coil voltages of } 1 \text { phase }}
\end{aligned}
$$

Equation 1 also applies to the running phase of a single-phase motor.

Application of Equation 1 to a 115 volt single-phase motor and then to a 920 volt motor of the same type in a size motor where Eph approximately equals 0.9 times the terminal voltage per phase, for a constant $\emptyset$ value, shows that for the same winding layout, the 920 volt motor would require $\frac{920}{115}=8$ times as many series turns per phase. For the same amount of copper, this requires a winding with 9 AWG wire sizes finer wire. With fine wire sizes, the space factor of the wire could be much less. Also, since motors must withstand twice the rated voltage plus 1000 volts to ground for 1 minute, more slot and interphase insulation must be used at a sacrifice of copper winding space. The overall poorer space factor of such high voltage motors may require a larger frame size to allow for increased flux and winding space.

High voltage motors have coils which are more expensive to wind because of the greater number of turns per coil. In some sizes, there would also be greater danger of wire breakage and resulting open circuits. 
No studies on the effect of higher voltages on efficiency and power factor were found in the published literature.

The possibility of using three-phase motors in conjunction with phase converters for residential and light commercial applications should be considered particularly for voltages over about 230 volts. It might well be that for some of the larger motors, voltages above the 920 volt target would be realistic.

Consider the relative advantages of using a three-phase motor instead of a capacitor start motor where the motor's physical size is the same in both cases. Suppose the main phase voltage of the capacitor start motor is 120 volts and the line-to-neutral voltage of the three-phase motor is 120 volts (208 volts line-toline). Assume the motor to have 24 stator slots and 24 coils. For running conditions, the capacitor-start motor operates on 12 series coils and the threephase motor on 24 ( 8 per phase). If both motors are operated at the same flux and about the same $K_{d} K_{p}$ value, the series turns per phase would be as follows, from Equation 1:

for the capacitor start motor:

$$
\begin{aligned}
\mathrm{Nph}_{1} & =\frac{\mathrm{Eph}_{1}}{4.44 \mathrm{f} \mathrm{K}_{\mathrm{d}} \mathrm{K}_{\mathrm{p}}} \text {, and the turns/coil }=\frac{\mathrm{Nph}_{1}}{12}=\frac{\mathrm{Eph}_{1}}{4.44 \times 12 \mathrm{f} \mathrm{K} \mathrm{K}_{\mathrm{p}}}= \\
& =.01877 \frac{\mathrm{Eph}_{\mathrm{ph}}}{\mathrm{f} \mathrm{K} \mathrm{K}_{\mathrm{p}}}
\end{aligned}
$$

for the three-phase motor: 


$$
\begin{aligned}
\mathrm{Nph}_{3} & =\frac{\mathrm{Eph}_{3}}{4.44 \times \mathrm{f} \mathrm{K}_{\mathrm{d}} \mathrm{K}_{\mathrm{p}}} \text {, and the turns/coil }=\frac{\mathrm{Nph}_{3}}{8}=\frac{\mathrm{Eph}_{3}}{4.44 \times 8 \mathrm{~K}_{\mathrm{d}} \mathrm{K}_{\mathrm{p}}}= \\
& =.02815 \frac{\mathrm{Eph}_{3}}{\mathrm{f} \mathrm{K}_{\mathrm{d}} \mathrm{K}_{\mathrm{p}}}
\end{aligned}
$$

For the same power being taken by the two designs (same efficiency, power factor and output assumed), the current draw of the capacitor motor is

$$
I_{1}=\frac{\text { watts input }}{120 \times \text { power factor }} \text {. }
$$

For the three-phase motor, wye-connected, the phase current is

$$
I_{3}=\frac{\text { watts input }}{3 \times 120 \times \text { power factor }} \text {. }
$$

It has been seen that $I_{3}=I_{1} / 3$. It has also been shown that the

$$
\mathrm{Nph}_{3}=\frac{.02815}{.01877} \mathrm{Nph}_{1}=1.5 \mathrm{Nph}_{1} \text {. }
$$

The 208 volt, 3-phase design would have about 58 percent more turns of wire with $\frac{1}{1.58}=.633$ times the cross-section in the single-phase design. The threephase unit must carry about one-third as much current through wire of .633 times as great cross section, resulting in greatly reduced current density. To compensate for the reduced current density in the three-phase unit, a shorter motor stator can be used. This would reduce the flux per pole and make the three-phase unit require more turns of finer wire. This would make the current densities in the three-phase design more reasonable and would result in a smaller motor.

In considering the improvements which may result from using three-phase motors and phase converters, one must consider the overall cost of the combination. Three-phase motors in themselves are more efficient than single-phase 
motors. A 70 percent efficient $0.25 \mathrm{~kW}$ motor takes about 100 watts less than a 55 percent efficient motor. If the price of electricity is $\$ .05$ per $\mathrm{kWh}$, the more efficient motor would save $\$ 5.00$ for each 1,000 hours of operation. Thus, if the more efficient motor costs $\$ 30$ extra, this investment would be paid back in about 9 months if the motor runs continuously. In a typical refrigerating machine, the motor operates one-third to one-half of the time. In this case, the payback time would be about 18 to 27 months. If the price of energy rises; the more efficient motor would become more attractive.

A motor which is used infrequently, as in a power tool, would not offer much advantage if it were made more efficient except possibly to increase reliability and to improve resistance to periodic over loads while running.

Steps which can be taken to raise the efficiency of induction motors used in residential and light commercial applications are as follows:

1. Increasing the amount of copper in the stator will lower the stator resistance and thus lower the stator loss.

2. Reducing the turns in the stator slots would reduce stator resistance and stator copper loss. The penalties are higher starting current and higher flux densities.

3. By using increased air gaps, the tooth pulsation losses can be reduced at the expense of reduced power factor.

4. By going back to high silicon steel instead of the cold rolled steel laminations now in use, core losses can be reduced. This would involve a slight reduction in power factor.

5. Use of thinner laminations would reduce the eddy current component-of the core loss.

6. Use of larger rotor bar and end-ring sections will result in reduced rotor $I^{2} R$ loss. This may result in excessive starting current, reduced starting tor que and voltage reduction on starting.

7. Reduction or elimination of skew in the rotor bars may improve efficiency but can increase noise level.

8. Insulating rotor bars from the rotor reduces some losses. 
Because so many of the steps which can be taken to improve the efficiency of induction motors also cause a decrease in power factor, it is worth pointing out that a decrease in power factor leads to increased distribution losses. This occurs because the motor may draw increased current despite the improved efficiency. An effective method of overcoming this problem is to install power factor correction capacitors in parallel with the motor, as close to its terminals as possible.

It must be kept in mind that specifying high voltage for low power motors generally leads to motors which have both lower efficiencies and lower power factors.

Low-cost shaded pole motors, although very inefficient, offer a popular choice for easy-starting loads, such as fans. Millions of these motors are used to drive range hood, kitchen exhaust, window and attic fans. The small skeleton types are used to drive small fans for refrigerators, freezers, freezer display cases and business machines.

The turns required in the energized winding of the small skeleton types are:

$E=4.44 \mathrm{Nf} \emptyset \max$

where

$E=a$ fraction of the rms applied voltage equal to about 0.75

$\mathrm{f}=$ frequency of the applied voltage in $\mathrm{Hz}$.

$\emptyset_{\text {max }}=$ maximum value of the flux in webers.

$\mathrm{N}$. $=$ turns in energized winding.

If 920 volts are applied to the bobbin-wound coil instead of the usual 115 volts, about eight times as many turns would be required $(\mathrm{N})$, using wire of oneeighth the cross section. These motors already use rather fine wire. Going to finer wire in such a large jump and using more insulation between layers and to ground 
may make the motor too fragile and prone to failure or rejection during manufacture. It is not recommended that these motors be designed for voltages greater than 230 volts.

The universal motor is the workhouse of almost all houseware appliances. It has excellent starting torque and adapts itself to variable speed operations. Universal. motors are used almost exclusively in mixers; blenders, vacuum cleaners and many other portable appliances.

A universal motor is similar in all respects to a series $d-c$ motor. Factors such as electrical and magnetic conditions, mechanical condition of the commutator, carbon brush conditions and atmospheric conditions may influence commutation. In both the $d-c$ and universal motors, the armature conductors cutting across the magnetic field set up by the combined armature and field winding generate voltages in the short-circuited coils which are proportional to the speed of the armature, the flux being cut and the number of turns. However, in the universal motor there is a voltage induced in the coils undergoing commutation which results from the reversals of the main field flux. The coil undergoing commutation therefore acts as the secondary of a transformer.

In the United States, the predominant voltage used in designing universal motors is 115 volts, $60 \mathrm{~Hz}$. For export, these motors must operate on a-c of 50 or $60 \mathrm{~Hz}$, more commonly $50 \mathrm{~Hz}$. Many foreign countries have 200 to 250 volts a-c, and it is very difficult to obtain good commutation unless the motors are designed for these higher voltages. Design for voltages even as high as 230 volts, $60 \mathrm{~Hz}$ would mean adding more commutator bars and narrower brushes. These measures, however, result in weaker mechanical construction.

Even with the special measures taken to increase the voltage rating of a universal motor, it may be necessary to limit their voltage ratings to 230 volts, 
$60 \mathrm{~Hz}$. A study of the difficulties involved in raising the rated voltage makes it appear that 230 volts, $60 \mathrm{~Hz}$ should be the top voltage rating for universal motors, even if they are used side-by-side with other types of motors in which higher voltage ratings are suitable.

\subsubsection{A-C Watthour Meters}

If higher distribution voltages are to be used, one must be concerned with the availability of devices for measuring the energy consumed at these higher voltage levels. Ordinarily, such measurements are made with a-c watthour meters.

The principle of the a-c watthour meter is that of the squirrel-cage induction motor in which a rotating magnetic field is used to produce torque on a disk.

The resultant field of two alternating currents of equal frequency which are in time and space quadrature is a true rotating magnetic field. If two currents differ in phase by 90 electrical degrees and flow in two coils placed at right angles to each other, the magnetic fields produced by these coils will also differ by 90 electrical and space degrees. The field strength of each coil continually varies, but the resultant field due to both coils is constant in magnitude when the currents have equal rms values. If the currents are not equal in magnitude, the magnitude of the resultant flux will not be constant, but will depend on the instantaneous values of the currents. The combined flux of the two coils is progressive and continually shifting, approximating a rotating action.

The a-c watthour meter is designed so that the current and potential winding fluxes are displaced $90^{\circ}$ in space. The current coil current is in phase with the line current, but the potential coil current is practically 90 electrical degrees out of phase with the line potential because of the high inductance of this coil. Thus, the requirements for a rotating or shifting field are met, and in the meter this field is passed through a portion of the disk. Eddy currents are set up in the disk which react with the moving magnetic field, causing the disk to rotate. 
It is essential that the torque acting on the disk be at its maximum value when the load to be metered is noninductive and that the torque on inductive loads be proportional to the cosine of the phase angle between the load current and voltage.

The design of watthour meters for use up to 240 volts is qựite routine, and their design for voltages above this value presents no unusual problems. It is a simple matter to use instrument transformers in conjunction with watthour meters. There are two general classes of instrument transformers, potential transformers and current transformers. These transformers are used with meters and instruments for two reasons; first, as a protection to life from contact with high voltage circuits and second, to reduce the voltage and current applied to the meters to values that will permit practical design. In practice, it is generally desirable or necessary to use current transformers for currents in excess of 100 amperes and to use current and potential transformers for voltages in excess of 240 volts.

An instrument transformer delivers to the meter to which it is connected a voltage or current which is always proportional to the primary voltage or current, and it insulates the meter from line voltage. Generally, the secondary of a potential transformer is designed for 120 volts for those rated $25 \mathrm{kv}$ and below, and for 115 volts for those rated $34.5 \mathrm{kv}$ and above. The secondary of a current transformer generally is designed for 5 amperes at rated primary current.

The use of instrument transformers would make possible the use of fairly conventional watthour meters, but additional cost is involved which must be investigated. Watthour meters are made with many built-in adjustments which could certainly allow for any effects on calibration resulting from the use of current transformers. Mass production of instrument transformers which would be required for use with watthour meters on higher voltage distribution systems would undoubtedly greatly reduce the price of these components. 


\subsubsection{The Potential Impact of Electric Vehicles}

It is felt by potential manufacturers of electric vehicles that their main thrust in the short term should be to penetrate the second and third car market. An important aspect of the electric car for this study is its effect on the electric load profile, particularly in residential areas. The electric car could cause a significant increase in residential sector load and load growth. It is assumed that most users of electric vehicles will connect the charger overnight. Studies made by Pacific Gas and Electric Company in California have shown that highway traffic generally follows the electric demand during the day and night. In analyzing the time relationships of vehicle charging, the electric load peaks are likely to be offset by at least 30 minutes, since this is the average commuting time to most residences. The Pacific Gas and Electric Company's study further indicates that if electric vehicle use becomes widespread and people retain their present driving habits, electric vehicles will not present a load that would require new generating capacity for many years and that the number of on-the-road electric vehicles which would be connected for charging during peak-load periods would be negligible. However, this does not preclude the possibility of load shifts from industrial and commercial areas to residential areas in off-peak periods. Thus, while the effect of battery charging may not be very appreciable where total utility load is concerned, its effects on the residential load factor could be significant.

Consider employees leaving their jobs at a time when the loads in the industrial and light commercial sector are being greatly reduced. These employees are going to an area where they will contribute to an increased load in the residential sector. Ovens are turned on, television sets are used, etc. Perhaps in the future electric car chargers will be plugged in also. While the charger load may merely compensate for the reduction in load in the industrial sector from the 
point of view of the overall power system, the distribution systems covering residential areas may be overloaded. Thus, while the electric car may only even out total load peaks, it may, nevertheless, overburden the distribution systems serving predominantly residential areas.

Many different batteries are under development for electric vehicles, but all the papers searched agree that the only realistic type at present is the lead-acid battery. This presents problems in terms of structure and arrangement. Structural problems are related to the mass of the batteries. In general, the curb weight of most electric vehicles is divided about equally between batteries and the balance of the vehicle. The most obvious shortcoming of the lead-acid battery is its limited energy storage capability. This is why the current state-of-the-art leadacid battery is not considered suitable as the first car in a full-sized family. Other batteries now being developed are also deficient in the power and energy requirements of a 3,500 pound family car. One of the main contenders for a suitable battery for electric vehicle use is the sodium-sulfur battery, particularly because of an abundant supply of its constituents.

At the present time, there is a great deal of technical activity of an unpublished nature aimed at reducing charging time of electric car batteries. In order to recharge the batteries in less time, it is necessary to draw more power over a shorter period. This may act as an additional factor contributing to over loading residential distribution systems.

Since the interface between the electric distribution/utilization system and the electric car is the battery charger, it is important to study the effect of higher voltages on battery chargers. No study of this type was encountered in the literature search. If half-wave or full-wave rectification were used, the ratings of the diodes used would be affected adversely from a cost point of view. This will have to be investigated. 


\subsection{Economics and System Analysis/Optimization}

Throughout the history of the electric utility industry in the United States, there has been a steady downward trend in the average real cost of electric energy per $\mathrm{kWh}$ sold to customers. The decreasing cost trend of this flexible and convenient form of energy has been a major factor in both the rapid growth of the industry and the rising national standard of living. It would thus be desirable for the future of both the industry and the nation that this trend continue.

Since approximately 40 percent of the investment of electric utilities is in distribution facilities, the trend of distribution system costs will be a major factor in determining what customers must pay for electric energy in the future.

\subsubsection{Distribution Economics}

Distribution costs can be divided into the two categories of (1) investment costs and (2) annual costs. Investment costs consist of those expenses incurred by . the manufacture, construction or purchase as well as the installation not only of substations, overhead and underground lines, including line transformers and services, but also of other components, such as meters, installations and leased property on customers' premises, and street light and signal systems. The annual costs of distribution consist of fixed charges on investment and operation and maintenance expenses. Fixed charges include return on invested capital, depreciation, taxes and insurance.

In the past, average $\mathrm{kWh}$ use, distribution system investment and distribution operation and maintenance expenses per customer increased annually. However, because kWh use increased more rapidly than either investment or operation and maintenance expenses, the trends of distribution investment and expense per $\mathrm{kWh}$ were downward. The past trends of distribution costs have been influenced by a number of factors, some of which tend to decrease costs per $k$ Wh and others to 
increase them. In order to develop a realistic economic model of present and/or future distribution costs, it is necessary to examine each of these factors and consider whether its influence on future costs will be similar to its influence on past trends.

\subsubsection{Factors Affecting Distribution Costs}

The two principal factors that have made possible the decreasing trend in distribution cost per $\mathrm{kW}$ are increasing load density and technological progress. Historically, the load densities on distribution systems have been increasing as both customer densities and load per customer have increased. The effect of this increased load density is to permit more energy to be distributed per mile of distribution line, per substation, per line transformer, etc., offering the benefits of economies of scale. The capacities of these components can be increased to transmit the increased energy, and in the past, higher capacity components have cost less per unit of capacity.

Many technological advances have contributed to the downward trend of distribution costs in the past, such as the development of higher capacity components, the application of lower cost materials, mechanization of maintenance and operating procedures and optimization of system designs. Primary circuit capacities in particular have been increased by the use of larger conductors, higher power factors and, most importantly, higher primary distribution voltages. In combination with increased load density, this has made the use of larger substations supplied at higher transmission voltages economical, thus reducing substation and transmission cost per $\mathrm{kW}$. Overhead distribution costs have been reduced by such changes as the use of fewer higher-capacity, higher-voltage lines, the development of lower cost power capacitors, the substitution of aluminum for copper in conductors, and the use of smaller, more mechanized construction crews. 
Substantial cost reductions in underground distribution have also been achieved by such developments as pad-mounted and subsurface transformers, lower cost cables, and direct burial of cables. Other sources of savings that apply to both overhead and underground systems are developments such as the use of radio communication, super visory control, automation and digital computers.

The principal factors that influence the trend of distribution costs in the upward direction are rising prices of materials and labor, increasing standards of service reliability, increasing cost and difficulty of acquiring and providing transmission supplies to properly-located substation sites and increasing costs of meeting location and appearance criteria for both lines and substations.

\subsubsection{Present Trends}

All of the latter factors that tend to increase distribution costs are expected to exert an ever-greater influence in the future. Moreover, it is expected that, although increasing load density and technological progress will continue to reduce distribution costs in the future, they will probably do so with some decrease in effectiveness, as they reach a point of diminishing returns. Some of the factors from which economies may not have been exhausted yet are the optimization of system design and/or distribution voltage levels, using computerized models. The use of higher distribution voltages may make fewer larger substations economical and thus reduce substation and transmission costs per $k W h$, if load density continues to increase as it has in the past. The latter condition is an important one, particularly since future load per customer may increase at a decreasing rate as the market for appliances utilizing electric energy approaches saturation. It is, therefore, important that accurate estimates of future load densities be made, in order to obtain realistic results from any model of distribution economics. As the price of fuel and the cost of capital escalate, energy losses are becoming a more 
significant factor contributing to the, increase in total distribution costs. An increase in the distribution voltage level could reduce losses materially, thus providing substantial energy savings. The early work in the evaluation of high voltage distribution gave only cursory consideration to energy losses and consequent savings, as they did not represent a significant portion of total distribution costs. Now that energy conservation has become a national objective and that escalating energy prices have justified it economically, the savings in losses have been quantified in more recent work. In most cases, however, only the fuel and other costs associated with generating lost power have been taken into consideration, while investment charges which are due to generation, transmission and distribution capacity necessary to supply losses have been neglected. A means for accurately assessing the magnitude and cost of these losses must thus be developed before they can be properly accounted for. Moreover, the effects of daily, weekly and seasonal load shape as well as the effects of step-by-step systems development in response to load grow th must be integrated into the evaluation of system losses.

In summary, it is generally. accepted that an economic analysis of high voltage distribution must compare present worth values of the decline in substation and line costs as well as energy losses to the consequent increase in equipment and reliability- or safety-related expenditures. However, both a reliable forecast of future load density and an accurate means of quantifying energy losses are essential to render any analysis realistic. These are either totally lacking or not generally accepted in the reviewed literature.

\subsubsection{Distribution and Utilization System Optimization}

Beginning in the early 1950 s with a general recognition of the necessity to convert to primary distribution voltages higher than $4 \mathrm{kV}$ due to load growth in congested urban areas with limited available underground and aerial rights-of-way 
and substation sites, the literature reflects a broad concern over both the technical problems and economics of such conversion, as discussed in the foregoing. Quantitative models designed to optimize or at least improve the choice of voltage levels are less abundant, but as the use of digital computers grew more widespread in the late 1950s and early 1960s, several attempts at developing such models were indeed made. The great majority of these studies, however, model either the transmission and/or primary voltage levels assuming that secondary voltages remain unchanged (Lawrence, Patton and Reps, 1960) and (Smith, 1961) or vice-versa (Campbell and Summott, 1957). Yet it is generally recognized that optimization, i.e., the seeking of the lowest overall system cost, cannot be achieved by linking together individual system-component designs obtained by optimizing each system component separately. One study (Campbell, Ender, Gaupel and Talley, 1960) does avoid this pitfall by considering economic system design from the primary feedpoint through the secondary system. However, in this as well as all the above-mentioned references, attention is focused on voltages up to $34.5 \mathrm{kv}$ which are now already in use. Furthermore, three-phase secondary voltages are explicitly excluded from this early work, whereas they are now considered as potentially more economical than single-phase voltages. Although load is extensively specified as a function of three terms: peak kva diversified demand per customer, saturation factor (the fraction of the total area served by a primary-feeder circuit containing lots that are occupied by homes) and void factor (the fraction of the total system area that is covered electrically by primary-feeder circuits), load growth, where considered, is simply assumed to be exponential. This may be far from accurate now, as the results of the $29^{\text {th }}$ electric industry annual for ecast seem to indicate. Finally, and perhaps most importantly, energy losses were largely assumed to be negligible in these early voltage conversion studies and were thus either disregarded or met with simplified treatment. 
Escalating fuel prices and international concern over energy conservation were important motivating factors for the more recent work (of the mid-1970s) on high voltage distribution, as well as increasing load forecasts. Consequently, considerable attention has been given to the evaluation and impact of energy losses in recent work.

However, there exists no generally accepted method for treating energy losses once they have been estimated, and as pointed out in a recent Norwegian article (Fredriksen, 1977) four different possible points of view can lead to a wide range of approaches. The pure "design" point of view is that which was widely used when energy costs were low and thus disregarded, implying high energy losses. As fuel prices have increased, the utility's point of view has gradually shifted to setting the cost of estimated losses equal to the wholesale cost of energy, which is to its own economic advantage and does contribute to a reduction in energy losses. This approach, however, does not take into account the externalities involved, such as safety or emissions control considerations, balance of trade, etc. A higher level of social welfare would be achieved by adopting the national economy's point of view, thus setting the cost of energy losses equal to the marginal cost of $\mathrm{kW}$ production and including externalities in the tradeoff. Although even greater savings could be obtained by adopting a purely energy conservation objective, this is considered uneconomic. Fredriksen's results indicate that the energy savings to be gained by adopting the national economy's point of view are relatively small but nevertheless very real. Moreover, his analysis is limited to specific $11 \mathrm{kV}$ and 22 kV distribution systems, and greater savings can be anticipated at higher voltage levels.

Other recent work (Park, 1974 and Gil, 1973) has shown appreciable longrange savings associated with a changeover to a $35 \mathrm{kv}$ distribution level, but has 
restricted its studies to that one possible change in voltage level and has been utility-specific. There thus remains a definite need in the field for a more general optimization methodology, both with respect to the design points considered and to the domain of applicability. 


\section{POTENTIAL ADVANTAGES AND DISADVANTAGES OF HIGHER DISTRIBUTION/UTILIZATION VOLTAGES}

\subsection{Primary and Secondary Distribution System}

\subsubsection{Advantages of Higher Primary Voltages}

The use of higher primary distribution voltages can result in the following advantages:-

- Both investment and fuel waste can be decreased by a reduction - in energy losses. The former is due to reduced capital investment in generation and transmission capacity required to supply the energy dissipated in the distribution system and the latter obtains from the fuel that must be burned to provide this energy.

- Lower current levels are required to supply load at higher voltages. These result in lower circuit losses.

- Lower transformer losses result from the possible elimination of one voltage transformation and larger transformer sizes which are economic with higher primary voltages and have lower core losses per $\mathrm{kVa}$ of rated capacity.

Fewer, higher capacity substations and circuits yield a number of benefits.

- The amount of substation land needed and associated separate right-ofway requirements for supply transmission are reduced. (Distribution circuits do not, in general, require individual rights-of-way.)

- Circuit congestion is reduced in the vicinity of each substation.

- Less underground duct is required, and more aesthetic pole-top design can be adopted because of fewer circuits.

- Fewer facilities reduce maintenance costs and manpower requirements.

- Economies of scale are realized in the purchase of larger transformers and in the construction of larger substations.

- Greater circuit capacity provides reserve useful in areas of high load growth. Reserve capacity also provides load transfer capability and thus reinforces system reliability.

- Voltage regulation is improved and consequently, circuit reach is increased. Circuit length is also less likely to be limited by a maximum voltage drop criterion, which is especially important in rural areas char acterized by dispersed concentrations of load. 
- Voltage regulation costs are reduced.

- Tolerance to the magnitude of load unbalance among the three phases of the main primary circuit is increased.

- Copper and aluminum costs are reduced because of the additional loadcarrying capability of higher voltage primary conductors.

\subsubsection{Advantages of Higher Secondary Voltages}

The advantages of higher secondary distribution voltages include the following:

- Investment and fuel waste are reduced with a reduction in energy losses.

- Voltage regulation is improved and secondary circuit reach is increased.

- Voltage fluctuation during momentary load increases is reduced.

High secondary voltages entail the use of larger distribution transformers which have lower core losses, display economies of scale, are more likely to exploit area load diversity, and are more aesthetic than a larger number of smaller transformers.

- Longer secondary reach may reduce the length of more expensive primary circuits.

- Copper and aluminum costs are reduced because of the additional loadcarrying capability of higher voltage secondary conductors.

\subsubsection{Disadvantages of Higher Primary Voltages}

The disadvantages of higher primary distribution voltages include the following:

The likelihood of more extensive interruptions of service increases due to the generally greater exposure to random faults of longer lines with greater load-carrying capability. The extent of an interruption may be reduced through greater investment in circuit sectionalization capability to isolate a fault rapidly, and/or in load transfer capability to restore service to isolated unfaulted sections immediately.

Coordinating the rating and installation of voltage surge arrestors with the basic insulation level of equipment and apparatus becomes more difficult. The length of arrestor leads becomes critical with higher primary voltages and is especially a problem with underground circuits.

- The insulation required to satisfy basic insulation levels in transformers, circuit breakers and cables becomes a more significant portion of the equipment cost with primary voltages. 
- Steps may have to be taken to limit excessive available fault currents to comply with the capability of consumer protective equipment. Higher fault currents may arise from a reduction in source impedance as a consequence of the elimination of one stage of voltage transformation.

- Safety considerations may require expenses to cover increased lineman training, increased lineman pay, and design and operating requirements to allow circuit deenergization for maintenance with minimal interruption in consumer service.

- Additional costs are incurred to prevent radio, television and telephone interference.

- Maintenance costs are increased and aesthetics reduced to maintain adequate tree clearances for higher voltage, aerial, open-w ire circuits.

\subsubsection{Disadvantages of Higher Secondary Voltages}

The disadvantages of higher secondary distribution voltages include the following:

- Higher available fault energies require reinforcement of utility and consumer fault protection equipment.

- Longer secondary circuits result in increased exposure to faults.

\subsection{End Use Elements}

\subsubsection{Advantages of Higher Secondary Voltages}

The advantages of higher voltages in end use elements include the following:

- The demand on the wire system is reduced and leads to savings in copper, in energy use and in expenses, due to lower current ratings.

- Energy losses decrease with the reduction in the step down from the distribution to the utilization voltage.

- Energy use and costs may be decreased by the elimination of intermediate voltage transformers to supply residential and light-commercial customers.

\subsubsection{Disadvantages of Higher Secondary Voltages}

The disadvantages of higher voltages in end use elements include the following:

- Additional measures of precaution are necessary to ensure the safety and reliability of equipment. Ground fault circuit interruptors may 
have to be installed on the individual appliances or in each building once higher voltages increase the chance of fault occurrences. Moreover, either safety sockets or autotransformers may have to be required for convenience outlets.

- For voltages such as $920 \mathrm{~V}$, wire gauges are required which are too fine to be used in practice for small motors. Finer wire has a poorer space factor than heavier wire. Its use results in decreased motor efficiency. The increased number of wire turns and amount of insulation required for high voltage also increases the motor frame size and thus its production costs. The alternative of increasing the flux densities in the magnetic circuit to minimize the number of wire turns required results in higher mechanical stresses.

- Starting capacitors for motors are presently only available in 130 volt ratings and have to be redesigned for higher voltages.

- Thermal overload protectors have to be designed for voltages over 230 volt and approved by the Underwriters' Laboratories, as they are not generally available at present.

- The use of voltages above 220 volts in universal motors of conventional construction may prove to be infeasible, as it requires higher bar-to-bar and commutation or reactance voltages than are permissible. 


\section{BIBLIOGRAPHY}

\subsection{Primary and Secondary Distribution System}

Anderson, A. S., V. A. Thieman, "Distribution Secondary Conductor Economics," AIEE Trans. PAS, Volume 78, pp. 1839-43, 1959.

Considers the problem of determining the lowest cost combination of distribution transformers and secondaries for a given load per customer. Equates an expression for the cost of losses with the investment cost for the conductor to compute the most economic conductor size. For changing load, a levelized loss cost over a period of time is used. Calculations are made for various lengths of secondary in order to determine the most economical transformer/secondary combination.

Burandt, R. P., J. A. Hughes, A. D. Patton and D. N. Reps, "Present-Worth Approach for Optimizing Distribution Transformer and Secondary Designs to Serve Growing Loads," AIEE Trans. PAS, Volume 80, pp. 345-55, 1961.

Optimization approached through cut-and-try method according to specified policies and plans in response to specified load patterns. Ranks all feasible expansions according to present worth of investments over the study period for different load densities and load growths. Relies on the design criteria that secondary voltage drop and loading will not limit the design before the distribution transformer reaches its maximum loading. In its conclusion, lists some important questions in the optimization of transformer/secondary design.

Cámpbell, H.E., R. C. Ender, M. W. Gangel and V. C. Talley, "Economic Analysis of Distribution Systems," AIEE Trans. PAS, Volume 79, pp. 423-43, 1960.

See Section 4.3.

Campbell, H.E., H.E. Sinnott, "Economic Analysis of Residential Secondary Distribution Systems," AIEE Trans. PAS, Volume 76, pp. 574-85, 1957.

See-Section 4.3.

Chang, N. E., "Determination of Primary Feeder Losses," IEEE Trans. PAS, Volume 87, p. $1991,1968$.

A method is presented for determining power and energy losses in primary feeders and a plan is described for mechanized data collection and processing for the determination of losses. This method requires the availability of a transformer load monitoring program and a large computerized data base.

Chang, N. E., "Determination and Evaluation of Distribution Transformer Losses of the Electric System Through Transformer Load Monitoring," IEEE Trans. PAS, Volume 89, p. 1282, 1970. 
A method of determining distribution transformer losses of the electric system at the time of system peak is described. A computer program which uses data from a transformer load monitoring program is described.

Chang, N. E., "Generalized Equations on Loss Reduction With Shunt Capacitors," IEEE Trans. PAS, Volume 91, p. 2189, 1972.

A mathematical analysis of shunt capacitor applications for loss reduction in distribution feeders is presented. Generalized equations for calculating loss reduction in a feeder are derived and the conditions for optimum loss reduction are developed.

Chang, N.E., "Determination of Secondary-Line and Service Losses of a Power System," Confer ence Paper C73 191 -4, IEEE Winter Power Meeting, 1973.

Statistical sampling of loads and impedances is used to estimate peak load loss for an entire system. A transformer load management program is used for computing the secondary line losses.

Comellini, E. and P. L. Noferi, "Distribution Line Optimization," Paper 4.7, CIRED Conference (IEE Conference Publication 151), London, 1977.

This paper develops formulae for present worth costs of line installation and losses. It also suggests a reasonable general formula for cost of line installation versus cross section of line. Formulae for selection of optimal current densities (and therefore cross sections) are developed. System expansion strategies for various grow th rates are suggested.

Gay, R. J., "Reliability and Overcurrent Protection of High Voltage Distribution Systems," Proceedings of Control of Power Systems Conference, Oklahoma City, Oklahoma, pp. 27-31, 1978.

Recognizing that economics dictate that higher feeder loadings must accompany the use of higher primary voltages, the importance of automatic circuit sectionalization and load transfer is emphasized to maintain service reliability comparable to that provided using lower primary voltages. Overcurrent protection is offered through the use of breakers, reclosers and fuses. In combination with voltage- or current-sensing sectionalizers, they operate to limit the effects of a fault. Discusses the reliability implications of the specific choice of equipment used in automatic circuit sectionalization and load transfer.

Giedlinski, A. M., "Size Your Conductors to Cut Losses, Costs," Transmission and Distribution, Volume 30, No. 9, pp. 52-54, September 1978.

Describes the "break-even current" approach to conductor sizing. This approach finds the current level at which the additional cost of using a conductor with lower resistance is exactly offset by savings in $I$ R losses. A formula is given which is based on an expression described by R. K. Biggard of Baltimore Gas \& Electric Company. The discussion concerns only conductor sizing for new lines and not reconductoring existing lines. Growth rate and cost of losses are two important variables that are manipulated. Saw-tooth grow th rate is compared to constant grow th rate. 
Hazan, E., "Engineering Data: Electrical Characteristics of Bare Aluminum Conductors: AAC, AAAC (6201), 5005, ACSR, ACAR," Electrical Products Division of Kaiser. Aluminum \& Chemical Corporation, 1969.

This report describes the relationships between current and conductor temperature and between conductor temperature and resistance. It also contains tables of the resistance constants for conductors with different diameters which can be used to determine the resistance and temperature of a conductor when a particular current is flowing in it.

Hopkins, D. L. and D. R. Samson, "Useful Methods for Determining Primary Feed Points in Future Distribution System Planning," AIEE Trans. PAS, Volume 73, pp. 856-63, 1954.

Develops formulae useful in determining the number and location of distribution feed points. The relations between voltage drop, losses, conductor size, area and load density for two circuit patterns are given for an area of uniform load density. The economics of losses and length of conductor as a function of load density and circuit pattern are explored. A general comment is made concerning the economic desirability of operating the primary system with a low voltage drop between first and last customer on the primary system for high load densities.

Klein, K. W., "Computer Gives Economic Loading for Transformer and Secondary," Electrical World, Volume 152, pp. 83-85, November 30, 1959.

This article is concerned with the optimal sizing of distribution transformers in terms of initial and final loading levels, and of secondary circuit in terms of conductor size and length. The optimization is by enumeration. It is emphasized that loading levels should be dictated by economics and not by thermal limits. Also, the importance of careful evaluation of losses is stressed. It is observed that limitations in allowable voltage drop limit the length of the secondary circuit and may consequently constrain its optimal design.

Merlin, A. and H. Bade, "Search for a Minimum Loss Operating Spanning Tree Configuration in an Urban Power Distribution System," Fifth PSCC Proceedings, 1975.

Presents a strategy for minimizing losses in a distribution system by modifying the (radial) networks operational configuration for a given set of nodal loads. Confers a balance between the fields of action of the different source nodes to minimize losses. Assumes knowledge of nodal voltage magnitudes.

Mitchell, C. F., J. O. Sweeney and J. L. Cantwell, "An Economic Analysis of Distribution Transformer Application," AIEE Trans. PAS, Volume 79, pp. 11961202, 1958.

Similar to (Lawrence, Reps and Patton - 1, 1960), but by another principal consultant and supplier to the electric utility industry. 
Lawrence, R. F., D. N. Reps and A. D. Patton, "Distribution System Planning Through Optimized Design, I - Distribution Transformers and Secondaries, AIEE Trans. PAS, Volume 69, pp. 199-204, 1960.

See Section 4.3.

Lawrence, R. F., D. N. Reps and A. D. Patton, "Distribution System Planning Through Optimized Design, II - Comparative Economics of System Voltages," AIEE Trans. PAS, Volume 79, Pp. 204-23, 1960.

See Section 4.3.

Lister, Eugene C., "Ferroresonance on Distribution Systems," Transactions on Industry Applications, January/February 1973.

In this paper, the conditions under which ferroresonance occurs are discussed, and methods to minimize ferroresonance are suggested.

Nickel, D. L., Higher Voltage Distribution Systems," Transmission and Distribution, Volume 26, pp. 52-56, August 1974.

Provides a good overview of the technical issues and the potential benefits of the use of distribution voltages up to $34.5 \mathrm{kV}$. Discusses design requirements relating to suppression of ferroresonance, elimination of radio and television interference, maintaining reliability, limiting fault currents, voltage surge. protection, and the establishment of a basic insulation limit.

Park, O.E., 'Economic Model Evaluates Voltage Levels," Electrical World, Volume 182, pp. 56-59, July 15, 1974.

See Section 4.3.

Procario, J. C., "CG\&E Cites 34.5-kV Feeder Advantages," Transmission and Distribution, Volume 29, pp. 28-36, December 1977.

Discusses the features of $34.5 \mathrm{kV}$ as a primary distribution voltage and the means of overcoming the associated technical problems. The features cited. include lower losses and better voltage regulation with fewer capacitors. The technical problems discussed include ferroresonance, the specification of BIL and its coordination with the sparkover voltage of distribution arrestors, lightning performance, and fault-current protection.

Querubin, R., G. Cuervo and G. Navas, "On the Optimum Design of Radial Distribution Netw orks," Proceedings of PICA Conference, pp. 173-76, 1975.

The conductors for a radial system with given loads are chosen from given alternatives to minimize the costs of conductor and of energy losses. Constraints considered include voltage regulation and thermal limitation of circuits. A method of recursive implicit enumeration is used to find the optimal solution.

Makes use of the following assumptions: 
1. Cost of conductors varies linearly with cross-sectional area.

2. Cost of losses/unit length for a given current is directly proportional to ohmic resistance and thus inversely proportional to cross-sectional area.

3. Cost of structure is constant, independent of conductor size.

Uses a principle of telescopy: If the cross-sectional area of the given set of available conductors is a continuous variable, and if no regulation constraints are imposed, the optimal cross-sectional area is proportional to the current flowing through the line. In practice, telescopy holds when a line and its predecessor have the same length, but does not, in general, hold for lines of unequal lengths.

Schulz, N. R., "Distribution Primary Feeder I ${ }^{2} R$ Losses," IEEE Trans. PAS, Volume 97, p. 603, 1978.

This paper presents an analysis of $I^{2} R$ losses on idealized primary distribution system feeders. Comparisons are made of relative $I^{2} R$ losses in voltage drop limited and thermally limifed primary feeders operating at different voltage levels. The effect of $I^{2} R$ losses in single-phase lateral return current neutrals is treated.

Smith, J. A., "Economics of Primary Distribution Voltages of 4.16 Through 34.5 kV," AIEE Trans. PAS, Volume 80, pp. 670-83, 1961.

See Section 4.3.

Wall, D. L., G. L. Thompson and J. E. D. Northcote Green, "An Optimization Model for Planning Radial Distribution Networks," Paper F78 653-8, presented at the IEEE Summer Power Meeting, Los Arigeles, California, 1978.

A method is presented for planning the configuration of a radial primary distribution system using an upper-bounded transhipment algorithm. The objective function is the sum over all lines of one of three costs: (1) the physical length of the line, (2) its electrical resistance, or (3) a linear approximation of the cost of power losses and installation costs for a given line type.

This paper discusses a portion of the work performed under EPRI Project RP-570-1 which will be completed in 1979.

Wormer, F. C., "Some Aspects of Distribution Load Area Geometry," AIEE Trans. PAS, Volume 73, p. 1343, 1954.

This paper presents a formula for voltage drop and from it derives conditions under which maximum area coverage for voltage drop limited circuits will be obtained. It also derives conditions for minimum voltage drop on a thermally limited circuit. Other generalizations about circuit dimensions under varying load density and voltage conditions are made. 
Zimmerman, R. A. and H. E. Lokay, "Economic Comparison of Secondary Voltages; Single- and Three-Phase Distribution for Residential Areas," AIEE Trans. PAS, Volume 75, pp. 542-66, 1956.

See Section 4.3. 


\subsection{End Use Elements}

Blois, Stanley O., "Electric Vehicles, Energy and Elephants," Pacific Gas \& Electric Company, Conference Paper C74-410-7, 1974 IEEE Power Engineering Society Summer Meeting, p. 1-4, July 1974.

In this article, it is noted that 60 percent of all car trips are for less than five miles and 79 percent are for less than 10 miles.- This certainly favors electric vehicle use. It is claimed that existing lead acid batteries are capable of matching these driving patterns. The potential effect of the electric vehicle on the electric load is studied. It is concluded that if electric transportation becomes widespread and people retain their existing driving habits, electric vehicles will not present a load that would require the addition of new generating facilities for many years.

Calabrese, G. O., "Symmetrical Components Applied to Electr ic Networks," Ronald Press, 1959.

This text goes into the analysis of polyphase electrical systems under unbalanced conditions. The theory developed applies to the analysis of threephase induction motors operated from a single-phase line by means of a phase converter.

Castenschiold, Rene, "Ground Fault Protection of Electrical Systems With Emergency or Standby Power," IEEE Transactions on Industry Applications, pp. 517-23, November/December 1977.

Providing ground fault protection in electrical systems having alternate emergency can present serious problems unless adequate equipment is selected. Multiple neutral to ground connections may prevent adequate sensing of ground fault currents and may also cause nuisance tripping of. C.B. Various approaches are discussed.

Chhabra, R. L., L. H. Soderholm and L. F. Charity, "Determination of Autotransformer-Capacitor Phase Converter Parameters," IEEE Transactions on IGA, Volume 1A-9, pp. 41-45, January/February 1973.

This paper analyzes the theory of one type of phase converter used to make possible the operation of three-phase induction motors from a single-phase source. Operating experience with the circuit is described.

Derven, Ronald and Carol Nichols, "How to Cut Your Energy Bills," Structures Publishing Company, Farmington, Michigan, 1976.

This book goes into the energy requirements of practically all end-use equipment used in the home. Contains technical information on operation of equipment such as heat pumps, etc.

Douglas, David L., "The Impact of Advanced Batteries on Electric Power Generation," IEEE Energy Development, Pp. 37-40, 1974. 
Electric street vehicles and storage of off-peak electrical energy for use in periods of peak demand are two potentially important new markets for secondary batteries. Today's battery technology, best exemplified by the lead acid battery, cannot meet the requirements of either application. New battery systems under development promise performance and cost which will satisfy the needs of both, although successful accomplishment is five to ten years away. The implications for the electric utility industry are discussed.

Edison Electric Institute, "Electrical Metermen's Handbook," published by Edison Electric Institute, 1950.

This reference covers theory of operation, maintenance and adjustment procedures on all types of energy measuring instruments in general use by electric power companies.

Editors of Product Engineering, "The State of the Battery Art for Vehicles," Product Engineering, p. 83, September 1978.

To advance the state of the battery art for vehicles, the Department of Energy has at least three programs underway for research and development of batteries of nickel-zinc, lead acid and nickel-iron. Lead acid batteries seem to be preferred for electric vehicles. Batteries of this type now under development will allow a small car to have a 75 mile range. The goal is 800 to 1000 cycles of charge and discharge available. It appears unlikely that the goal of $165 \mathrm{~km}$ range between charges can be met with a lead acid batterypowered electric vehicle. General Motors is experimenting with a zinc nickel-oxide battery for improved range. Improvements in demand metering will be required so that the batteries can be recharged overnight when utility power is readily available and can be sold more cheaply. This type of metering by utilities is presently being done experimentally to a limited number of homes.

Huber, G. H., "Application and Effects of $15 \mathrm{HP}$ and Larger Three-Phase Motors on Single-Phase Lines," Conference Paper No. 34-CP-66-226, presented at Rural Electrification Conference, Dallas, Texas, May 1966.

This paper deals with operating characteristics of integral horsepower threephase motors when used with phase converters for use on single phase.

Kemper, Mark J., "Operating Experiences With Three-Phase Motors on SinglePhase Lines," IEEE Transactions on Industry and General Applications, Volume IGA-2, No. 6, pp. 443-45, November/December 1966.

This paper indicates that three-phase motors with converters have given excellent service in many applications involving motors up to $50 \mathrm{HP}$. Emphasis is mainly on the effect on inrush current.

Kerchner, R. M. and G. F. Corcoran, "Alternating-Current Circuits," Third Edition, John Wiley \& Sons, Inc., New York, New York, Pp. 377-89.

A very good description of the principle of operation of the watthour meter. Power factor errors, adjustments and calibration are discussed. Measurement 
of both single and polyphase energy are covered, including connections employing current and potential transformers.

Kinnard, Isaac F., "Applied Electrical Measurements," John Wiley \& Sons, New York, New York, pp. 186-201, 1962.

The principle of operation of the induction watthour meter is covered in considerable detail. Both single-phase and polyphase types are discussed.

Lamme, B. G., "A Theory of Commutation and Its Application to Commutating Pole Machines," AIEE Transactions, Volume 30, Part II, Pp. 2359-2431, 1911.

This classic paper develops a theory of commutation for dc machines which is also applicable to universal motors used in many household appliances. Lamme's theory of commutation introduced in this paper is still the basis for design of the commutator and brush systems at the Westinghouse Corporation.

Lamme, B. G., "Physical Limitations in DC Commutating Machinery," AIEE Transactions, Volume 34, Part II, Pp. 1739-1800, 1915.

This paper is an excellent study of the factors affecting good commutation in dc machines. Much that is in the paper is applicable to universal motors as well as de motors. The equations developed show the effect of voltage rating on commutation.

Lawn, Frank, "State of the Art on Battery Chargers," Conference Paper, IEEE 1974 Power Engineering Society Summer Meeting, pp. 1-3, June 1974.

Since the development of lead acid batteries, there has been a continual disagreement on the best method of charging these batteries. This paper will not end those disagreements, but it does explain some of the considerations involved in charging lead acid batteries, describes some of the methods that have been used, and suggests a method that seems to be applicable for a great number of batteries. It also suggests some considerations in the problem of charging batteries for fleets of electric vehicles. There is general agreement that most of the damage done to batteries occurs during the charge process and this process includes any float periods. There are a number of basic systems of charging, and an almost infinite number of variations on these systems. There is also a number of methods for determining the state of charge of a battery, all of which have some advantages and some disadvantages. As in all fields, cost is an important factor as well as proper reliable operation. The most commonly talked about methods of charge are the Constant Voltage and Constant Current Systems with a variety of modifications.

Little, Arthur D., Inc., "Energy Efficiency and Electric Motors," U.S. Department of Energy, April 1978.

Discusses energy consumption resulting from use of electric motors in industrial and commercial sectors and means of reducing this energy use. Stress is on improvement of motor efficiency through proper use of design factors. 
Miller, "Higher Voltage on Motors," Voltage Rating Versus Horsepower of Motors, pp. 306-11, November 1952.

Applying higher voltage to the same size of motor requires (1) higher number of turns/coil, i.e., more conductors per slot, (2) more turn to turn insulation and (3) more ground insulation.

Morton, William R. and T. C. Johnson, "Design Considerations for the Use of Aluminum Alloys for Integral Horsepower Motors," IEEE Transactions on Industry Applications," pp. 611-17, November/December 1977.

The comparison between using aluminum alloys for the external parts of induction motor is studied in this paper. The use of aluminum wire in stator windings is also discussed.

Morrill, Wayne J., "The Revolving Field Theory of the Capacitor Motor," AIEE Transactions, Volume 48, Pp. 614-32, 1929.

In this paper, the equivalent circuit of the capacitor motor based on the double revolving field theory is derived for the first time.

Packer, L. C., "Commutation in Universal-Type Motors," AIEE Transactions on Applications and Industry, Volume 20, pp. 170-76, 1951.

In this paper, it is pointed out that the universal motor, so commonly used in: portable home appliances, has the problem of both ac and dc motors. The many factors affecting satisfactory commutation are discussed. These are both mechanical and electrical in nature. The effect of higher design voltages on commutation is discussed from the view point of Lamme's theory of commutation. Methods of producing improved commutation in universal motors are discussed.

Packer, L. C., "Application of Motors to Household Refrigeration Compressors," AIEE Transactions on Applications and Industry," pp. 70-76, January 1952.

This paper discusses the types of motors best suited to application in household refrigerator compressors, power requirements, starting methods, protection from overheating, mechanical factors and causes of motor failure. Data presented apply mainly to equipment for present-day voltages, but the information presented is useful in the investigation of higher end-use voltages.

Salihi, Jalal T., 'Energy Requirements for Electric Cars and Their Impact on Electric Power Generation and Distribution Systems," IEEE Transactions on IGA, Volume I-A, Pp. 516-32, September/October 1973.

In this paper, the average energy requirement per mile of driving for a 2000 pound limited performance electric car powered by lead acid batteries is compared with the energy requirement for a conventional heat powered car of equal weight. It is concluded that the available electric cars consume only about one-half the energy requirement of a conventional heat engine car of equal weight. It is predicted that the energy consumption of electric cars may be reduced in the future. 
Scheuer, Paul R and Steven B. Sample, "Adjustable Threshold Electronic Motor Starting System," IEEE Transactions on Industry Applications," pp. 188-93, March/ April 1977.

This electronic operation is systematically isomorphic to the action of the motor starting relay. A fixed threshold voltage is established across the resistor from the power supply. When there is an increase or decrease in the input voltage, the difference between the input voltage and the threshold voltage causes the transistor to switch on, thus giving a command through a digital circuit to energize or deenergize the start winding. This system and the improved system are discussed in this paper.

Smith, Craig B., editor, "Efficient Electricity Use," report prepared by Applied Nucleonics, Inc., book published by Pergamon Press based. upon the above report, 1976.

On Pages 215-99, the different types of residential energy usage are discussed as well as the economics of residential electricity use.

Springer, George S. and Gene E. Smith, "The Energy Saving Guidebook," published by Technomic Publishing Company, Westport, Connecticut, 1974 :

Contains facts about energy consumption of end use devices.

Stenger, Harvey G., "Advances in Motor Protection for Small Hermetic Refrigerant Compressors," IEEE Transactions on Industry and General Applications," pp. 494-98, November/December 1966.

For hermetic air conditioning compressor.s, the use of inline internal motor protection makes it possible to directly protect the motor in its true operating environment. For this reason, the use of the internal line-break motor protector in single-phase air conditioning compressors is becoming popular. Ambient air temperatures, voltage variations and the strong influence of the surrounding refrigerant combine to set the duty requirements of the protector. Important factors in selecting, locating and testing these protection devices for proper operational and reliability standards are described.

Stevenson, John, "Leakage Current From Appliances,". IEEE Transactions on IGA, Volume 1A-9, No. 1, pp. 74-80, January/February 1973.

Leakage current refers to all currents, including capacitively-coupled currents which may be conveyed between accessible parts of a cord-connected appliance and ground or other accessible parts of an appliance. The current can pass through a person to ground or to other parts of the same appliance. Leakage current from portable appliances has been limited to 0.5 ma by ANSI Committee C101.1. In this paper, typical leakage currents are presented for many end-use elements. Effects of temperature, humidity, grounding, bonding and circuit conditions were measured.

Trickey, P. H., "Performance Calculation of Capacitor Motors," AIEE Transactions, Volume 60, pp. 73-76, February 1941. 
This paper outlines a calculation procedure for predicting the performance of capacitor motors. It is useful in generating computer programs such as those required for this study.

Veinott, Cyril, "Computer-Aided Design of Electric Machinery," MIT Press Book, 1972.

In this book, Dr. Veinott shows how the computer may be used to generate new motor designs. The information provided can also be used in setting up a program for studying the effects of such variables as design voltage. Emphasis is on computer-aided design of ac motors.

Weiss, Wolfgang, "Computer Study of Factors Affecting the Operation of a Permanent Split Capacitor Motor," M.S. Thesis, New Jersey Institute of Technology, 1978.

This thesis contains a FORTRAN IV program written by J. Winston for analyzing performance of permanent split capacitor motors when various design changes are made. Equivalent circuit values are the input data to the program and data for about 100 operating points are obtained. The effect of winding and voltage changes can be analyzed for effect on efficiency, power factor, speed, capacitor voltage, phase currents and capacitor phase voltage.

Whitt, Raymond O. D., "Trends and Practices in Grounding and Ground-Fault Protection Using Static Devices," IEEE Transactions on IGA, Volume 1A-9, No. 2, pp. 149-57, March/April 1973.

This paper identifies types of electrical distribution systems in use in both the grounded and ungrounded categories. With the advent of higher voltage levels in low voltage distribution systems and the trend towards solidlygrounded systems, problems resulting from the lack of proper ground-fault protective devices have caused equipment failures. Various methods of detecting ground faults using static devices are described.

Whitt, Raymond O. D., "A Better Approach to Motor Circuit Protection," IEEE Transactions on IGA, Volume 1A-9, pp. 278-84, May/June 1973.

This paper covers the requirements of adequate motor circuit protection, reviews the components used for motor circuit protection, discusses the level of motor circuit fault currents and presents a new method of achieving a better approach to motor circuit protection. 


\subsection{Economics and System Analysis/Optimization}

Campbell, H.E. and H. E. Sinnott, 'Economic Analysis of Residential Secondary Distribution Systems," AIEE Transactions, Volume 76, Part III, Pp. 574-75, 1957.

This paper analyzes the subject of whether the industry should go to a higher voltage secondary distribution system to service the residential-class load.

The scope of this paper is confined to a new area with new homes and to a continuation of the use of 120 volts in the home. The demand used in this study is varied from what is expected today for a home with all major appliances to few times that demand for the future. Secondary spans are taken as 140 and 200 feet in order to see the effect of lots with 70- and 100foot frontages on the economic relations of the various systems.

The secondary systems studied are 120/240-volt and 240/480-volt singlephase, and 240/416-volt and 277/480-volt 3-phase. Area secondary distribution costs as well as the present-day linear-type are studied in order to find the lowest cost system for each voltage and span length at each demand. A primary voltage of $34.5 \mathrm{kV}$ is used throughout.

Campbell, H. E., R. C. Ender, M. W. Gangel and V. C. Talley, 'Economic Analysis of Distribution Systems," AIEE Transactions, Volume 79, Part III, pp. 423-40, 1960.

This paper presents the results of a computer study of economic distribution design from the primary feedpoint through the secondary system. The purpose is to observe the design, the system components, and whatever trends may exist with regard to serving a range of residential load levels at different values of primary or secondary voltages. Substation and subtransmission system data are added to the results of the computer study where they are influential in helping to determine economic design and loading practices beyond the feedpoint in the distribution system. The study is based primarily on initial system design to serve a specific load level. Load and system grow th considerations are also discussed.

DeHaan, K., "Some Considerations for Economizing on Distribution Networks," Holectechniek (Netherlands), Volume 5, No. 2, pp. 36-41, 1975.

The historical development of distribution networks, present-day problems and the increasing demand expected for the future, lead to the idea of introducing a high voltage distribution network (100-150 kV) in urban areas. The M.V. (10-20 kV) network can then be reduced to a simple distribution network for connecting M.V./L.V. (380 kV) transformers. This would give substantial economic advantages. However, a pure distribution network gives a limited supply area to a transformer point. The economy determines the optimum dimensions of this supply area. It is shown that reserve is needed in the M.V. network and H.V./M.V. transformation for protection against supply interruptions in cases of cable faults and transformer faults. In conclusion, losses and automation aspects are covered.

Editors of Electrical World, "29th Annual Electrical Industry Forecast," Electrical World, pp. 61-76, September 15, 1978. 
Federal Energy Administration in cooperation with National Energy Information Center, "Quarterly Report: Energy Information Report to Congress Required by Public Law 93-319, Amended by Public Law 94-163," NTISUB/B/027, 1976.

Resource development, coal, natural gas, crude oil, refined petroleum products, nuclear energy, and electric power are discussed. Topic areas cover such things as production, consumption, imports, exports and reserves.

Fredriksen, O., "Design Criteria and Losses in a High Voltage Distribution System," Elektroteknisk Tidsskrift (Norway), Volume 31, No. 1, p. 13, pp. 15-16, January 1978.

Technical and economic considerations in the design of a high voltage distribution system are discussed from the point of view of minimizing the losses. An example is given for a $22 \mathrm{kV}$ system.

Gil, E. E., "Change to 35 kV Proves Economical," Electrical World, pp. 76-77, December 1973.

Converting to $35 \mathrm{kV}$ will save Houston Lighting and Power Company about 6 percent compared to absorbing grow th on the present $12 \mathrm{kV}$ system. This conclusion was the result of an area study presented at the Power Distribution Conference in Austin in 1973, which is briefly summarized in this article.

Goen, Richard L. and Ronald K. White, "Comparison of Energy Consumption Between West Germany and the United States - Final Report," Stanford Research Institute, Technical Report of the Federal Energy Administration, Report No. NTIS-PB-245 652/3B A, June 1975.

The report examines and explains the differences in per capita energy consumption between the United States and West Germany, and quantifies the factors involved. West Germany uses only half as much energy per capita as the United States. Energy use per capita for transportation is only onefourth of that of the United States, for residential space heating (climate corrected) only one-half. The United States uses at least 40 percent more energy for industry in relation to output as West Germany. The total energy use in the United States in relation to national income is about 50 percent greater than in West Germany. This large disparity in energy use between the two countries suggests that continued economic grow th and improvement in the standard of living in the United States should be possible without a proportionate increase in energy consumption.

Grisconi, S. B. and R. F. Lawrence, "Residential Distribution - An Analysis of Systems to Service Expanding Loads," AIEE Transactions, Volume 75, Part III, pp. $533-42,1956$.

This paper attempts to state and analyze some of the many factors involved in the residential distribution problem. The authors conclude by expressing their personal opinions as to the course most advantageous in the long run to both consumers and the electrical utility.

Heumann, K., "Power Electronics in Energy Production and Distribution, III -Limits of Application," Tech. Rundsch. (Switzerland), Volume 68, No. 23, pp. 17-19, 1976. 
Current engineering practice, dealing with motor drives, power network coupling, high-voltage-dc power transmission, semi-conductor circuit breakers and power-factor correction are discussed.

Hucaluk, F. K, "High Voltage Power in Industrial Plants," Modern Power and Engineering (Canada), Volume 71, No. 8, Pp. 22-23, 1977.

The first in a new series on industrial electrical systems, this article shows how selection of high voltage distribution systems for plants can affect costs and system reliability.

Hunt, Robert E, Frank Seabury and Philip F. Valence, "Energy Efficiency and Electric Motors - Final Report," Arthur D. Little, Inc., Technical Report of the Federal Energy Administration, August 1976.

The report identifies areas of greatest energy conservation potential in electric motor use in the industrial and commercial sectors of the economy; assesses and projects the technological potential and economic trends that might influence the use of more efficient electric motors; and outlines possible government strategies encouraging such use. It reports that the 1 to $125 \mathrm{hp}$ polyphase motors were the predominant energy consumer.s, accounting for about 26 percent of the total electric power generated in the United States. Estimates of their potential for increased efficiency, coupled with possible replacement rates of lower to higher efficiency motors, indicated potential savings by 1990 of 35 billion $\mathrm{kWh} /$ year--or 60 million barrels of oil.

Kujszczyk, S and S. Taleb, "The Design Algorithms of Electric Power Loop Networks," Arch. Elektrotech. (Poland), Volume 26, No. 2, pp. 301-13, 1977.

New methods of optimal design of loop high-voltage and low-voltage..power networks are described in the paper. The first method is for design of a oneloop network, a second one for a several loop network.

Lawrence, R. F., D. N. Reps and A. D. Patton, "Distribution System Planning Through Optimized System Design, Part I - Distribution Transformers and Secondaries," AIEE Transactions, Volume 79, Part III, Pp. 199-204, 1960.

This paper presents a method of finding the most economical distribution transformer and secondary combination through the use of a computer program. The method of solution is to select a range of transformer ratings, secondary conductor sizes, and number of connected customers and try all possible combinations of these variables. The most economical design is that combination having the lowest cost within operating and service-quality .. limits.

Lawrence, R. F., D. N. Reps and A. D. Patton, "Distribution System Planning Through Optimized System Design, Part II - Comparative Economics of System Voltages," AIEE Transactions, Volume 79, Part III, pp. 204-13, 1960.

This paper reports the results of a study having the objective of determining the optimum combination of primary-feeder and subtransmission voltages. Distribution systems to serve new urban and suburban areas of predominantly 
residential load are considered. The systems are entirely of overhead construction. Only the conventional secondary utilization-voltage level of $120 / 240$ volts is included in the analysis.

Minford, D. E., "Alternate Distribution Voltages," IEEE 1977 Rural Electric Power Conference," 1977.

This paper first reviews the long-range planning bases for the decision to convert all or portions of existing 7.2/12.5 kV distribution systems to $14.4 / 24.9 \mathrm{kV}$ operation. It then relates conversion experience on some actual midwest rural systems and provides guidelines to determine when and which portions of the system should be converted in construction work plans. Planning and operating problems on mixed 7.2/12.5 kV-14.4/24.9 kV systems are discussed as well as benefits resulting from conversion.

Park, O.E., "Economic Model Evaluates Voltage Level," Electrical World, Pp. 56-59, July 15, 1974.

Briefly describes a generalized econometric model derived for electric distribution systems and illustrates some results of its application to systems with primary voltages of 13.8 and $34.5 \mathrm{kV}$. The article suggests the usefulness of such a model, but is too brief to develop any confidence in its validity.

Rappeport, Michael and Patricia Labaw, "Trends in Energy Consumption and Attitudes Toward the Energy Shortage Highlight Report," Opinion Research Corporation, Technical Report of the Federal Energy Administration, Report No. NTIS-PB-244 983/3BA, December 1974.

This report is a part of a series of studies dealing with general public behavior and attitudes towards energy conservation. It concentrates on energy consumption and attitudes toward the energy shortage. The following issues are considered: seriousness of the energy shortage; duration of the energy shortage; perceived severity of the shortage; real versus contrived shortages; effect of shortages on the public; satisfaction with President Ford's energy measures; effort made to save energy; suspension of emission controls; and effect of energy shortages and resulting price increases on people's behavior, including use of electricity, use of cars influenced by shortages, use of cars influenced by price, leisure activities and hobbies at home.

Schultz, N. R., "Ten Years Experience With 35 kV, UD-Suppliers Viewpoint," IEEE 1976 Underground Transmission and Distribution, pp. 141-45, 1976.

The results of a survey covering 83 different major utilities concerning high voltage usage are presented. It is observed that 25 and $34.5 \mathrm{kV}$ now represent a growing and substantial portion of the underground distribution market. Current trends and practices are discussed and finally future needs are evaluated.

Shankle, D. F., "Incremental Voltage Uprating of Transmission Lines," IEEE Transactions, Volume 90, Part II, Pp. 1791-95, 1971. 
Many electric utilities face the problem of expanding transmission systems where new transmission line right-of-way (ROW) is increasingly more costly and difficult to obtain. One alternative is to uprate the voltage of lines on existing ROW to obtain increased transmission capacity. This paper discusses the technical and economic considerations of incrementally uprating the voltage of existing lines. Cost comparisons are made with building new lines on new ROW. There is a broad range of ROW costs and system transmission requirements where voltage uprating of existing transmission lines may.be economically attractive.

Smith, J. A., "Determination of Economical Distribution Substation Size," AIEE Transactions, Volume 80, Part III, Pp. 663-69, 1961.

This paper is intended to illustrate some of the principles. involved in the selection of substation size by comparing costs for new distribution systems installed overnight to serve various load densities under uniform or ideal conditions. Results obtained in this manner do not necessarily represent an actual system, but are useful for establishing guideposts for future expansion. This is accomplished by illustrating the effect of the different variables on total system cost as conditions are changed. While this method permits a better understanding of the relationship involved and helps establish benchmarks for future expansion, it neglects many important items. The influence of these must finally be taken into account, including the effects of nonuniformity, rate of load growth, time value of money and the existing system must be expanded in keeping with actual system demand.

Smith, J. A., "Economics of Primary Distribution Voltages of 4.16 Through 34.5 kV," AIEE Transactions, Volume 80, Part III, pp. 670-83, 1961.

An economic comparison is made of the traditionally used $4.16 \mathrm{kV}$ and 12.5 $\mathrm{kV}$ primary distribution voltages as well as higher voltages of $20.8 \mathrm{kV}, 23.0 \mathrm{kV}$ or $24.9 \cdot \mathrm{kV}$ and $34.5 \mathrm{kV}$ that have been more recently introduced. Starting from a common transmission or subtransmission voltage level from which power would fundamentally be made available to supply each of the distribution voltages to the customer, systems that utilize each voltage most economically, particularly with respect to distribution substation size, are compared.

Stanford Research Institute, "Patterns of Energy Consumption in the United States," Office of Science and Technology, Executive Office of the President, Washington, DC, 1972.

This report is strictly a factual document, its purpose is to provide the most detailed information practicable on the trends in energy consumption that have prevailed since 1960, of the important specific end uses in the residential, commerial and industrial sectors of the U.S. economy.

U.S. Bureau of the Census, "Statistical Abstract of the United States: 1977," U.S. Department of Commerce, Washington, DC, 1977.

The statistical abstract of the United States, published annually, - is the standard summary of statistics on the social, political and economic organization of the United States. Pages 462, 784, 823 and 825 present data on 
sales, saturation in U.S. households and retail values of selected electric appliances.

Walukas, D. J., "Assessing the Potential for Optimal Utilization of Off-Peak Power, Volume II - Electrical Loads Offering Major Potential for the Use of OffPeak Power," Westinghouse Research Laboratories, Technical Report of the Federal Energy Administration, Report No. NTIS-PB-254 775/OBA, December 1975.

This report describes Tasks 1 and 2 of a one-year study and demonstration for assessing the potential for optimal utilization of off-peak power. Three subtasks were performed in the completion of Task 1: (1) study all of the major end uses of electric power; (2) determine the major potential uses of off-peak power; and (3) describe historical patterns of operation and make future projections. The effort in Task 2 was divided into three subtasks: (1) analyze potential off-peak power use option for (a) economic considerations to the utility, builder or manufacturer, and uses, (b) design characteristics, including safety, comfort, bulk/weight, and esthetics, (c) effects on the environment, (d) implementation problems and solutions, (e) research and long-term development required for implementation, and (f) economic, employment and social costs and benefits; (2) describe the energy conservation potential of each off-peak power use option; and (3) determine the off-peak power use option best suited for a pilot demonstration.

Woromak, Alexander and John J. Murphy, "Economic Impact Study of the Appliance Efficiency Program," Infodyne Systems, Inc., Technical Report of the Federal Energy Administration, Report No. NTIS-PB-251 665/6B A, June 1975.

This report analyzes the economic impact of technical improvements that would have to be incorporated into major household appliances to make 1980 models provide the same level of performance as 1972 models, but require on the average 20 percent less energy to operate. The appliances covered by the efficiency program and their specific energy efficiency goal objectives for 1980 are: room air conditioners; electric and gas water heaters; refrigerators and refrigerator/freezers; freezers; electric and gas ranges; electric and gas dryers; washers, dishwashers; and black and white and color televisions.

Zimmerman, R. A. and H. E. Lokay, "Economic Comparison of Secondary Voltages, Single- and Three-Phase Distribution for Residential Areas," AIEE Transactions, Volume 75, Part III, pp. 542-66, 1956.

The high cost of serving heavy residential loads with the conventional 120/240-volt radial system indicates that other system possibilities and voltages should be explored. The use of higher secondary voltages in commercial areas suggests that the potentialities of higher voltage systems be studied for residential areas. The purpose of this paper is to present and compare the results of such studies with the results of studies of the conventional 120/240-volt radial system. 